\title{
RANCANG BANGUN ALAT UKUR PANJANG KAKI DAN PENENTU STOK SEPATU YANG TERSEDIA SECARA DIGITAL MENGGUNAKAN ARDUINO MEGA 2560 BERBASIS WEBSITE
}

\author{
[1]Asep Hermawan, [2]Abdul Muid, [3] Irma Nirmala \\ [1] [3]Jurusan Rekayasa Sistem Komputer, Fakultas MIPA Universitas Tanjungpura \\ [2]Jurusan Fisika, Fakultas MIPA Universitas Tanjungpura \\ Jalan Prof. Dr. H. Hadari Nawawi, Pontianak \\ Telp./Fax.: (0561) 577963 \\ hrmwn035@gmail.com
}

\begin{abstract}
Shoes have become a necessity and human lifestyle in keeping with the times. The main function of the shoe is to protect the foot from being injured due to environmental conditions. Shoe size is also a factor that influences the safety and comfort of activities so that the right size shoes are needed.For the sake of comfort in doing activities, shoes with the right size are needed to reduce injury. Some foot injuries can be caused due to incorrect selection of shoes so that they have a bad impact on the feet. To answer these problem, digital foot length measuring device will be made in this study using LDR sensor and diodesIn addition, this device can also recommend the right shoe sizes from various shoe brands available on the website page. To connect supporting software and hardware it will be managed by Arduino MEGA. Test results on 40 samples indicate that the system can recommend shoe sizes to users with a high level of suitability. Digital device test results obtained difference between $0 \mathrm{~cm}-1 \mathrm{~cm}$ with a tolerance value of $1 \mathrm{~cm}$. On manual measurements of user's foot length and shoe size obtained a difference between $0,4 \mathrm{~cm}-1,5 \mathrm{~cm}$ with a tolerance value of $1,5 \mathrm{~cm}$.
\end{abstract}

Keywords: Shoe Size, LDR Sensor, Arduino MEGA, Website

\begin{abstract}
Abstrak
Sepatu sudah menjadi kebutuhan dan gaya hidup manusia dalam mengikuti perkembangan zaman. Fungsi utama sepatu adalah melindungi kaki agar tidak cedera karena kondisi lingkungan. Ukuran sepatu juga menjadi faktor yang mempengaruhi keamanan dan kenyamanan dalam beraktivitas sehingga dibutuhkan sepatu dengan ukuran yang tepat. Beberapa cedera kaki dapat disebabkan karena salah dalam pemilihan ukuran sepatu sehingga berdampak buruk bagi kaki. Untuk menjawab permasalahan tersebut, dalam penelitian ini direalisasikan alat ukur panjang telapak kaki secara digital menggunakan sensor LDR dan Dioda. Selain itu alat ini juga dapat merekomendasikan ukuran sepatu yang tepat dari berbagai merek sepatu yang tersedia di halaman website. Untuk menghubungkan perangkat lunak dan perangkat keras pendukung maka akan diatur oleh Arduino MEGA. Hasil pengujian pada 40 sampel menunjukkan bahwa sistem dapat merekomendasikan
\end{abstract}


ukuran sepatu kepada pengguna dengan tingkat kesesuaian yang tinggi. Pengujian alat digital diperoleh selisih antara $0 \mathrm{~cm}-1 \mathrm{~cm}$ dengan nilai toleransi sebesar $1 \mathrm{~cm}$. Untuk pengukuran manual panjang kaki dan ukuran sepatu pengguna didapatkan selisih antara $0,4 \mathrm{~cm}-1,5 \mathrm{~cm}$ dengan nilai toleransi sebesar $1,5 \mathrm{~cm}$.

Kata kunci : Ukuran Sepatu, Sensor LDR, Arduino MEGA, Website

\section{PENDAHULUAN}

Kemampuan menggunakan teknologi produksi secara tepat adalah faktor yang mempengaruhi kemampuan bersaing industri [1]. Dalam perkembangan manajemen modern, teknologi informasi berkembang dengan sangat cepat. Adapun komputer yang merupakan peralatan yang diciptakan untuk mempermudah pekerjaan manusia, saat mencapai kemajuan baik dalam pembuatan hardware maupun software [2]. Kemajuan teknologi sangat membantu dalam setiap pekerjaan manusia, seperti di pabrik industri yang sudah banyak menggunakan kerja mesin untuk melakukan produksi perakitan, pengepakan barang dan pengemasan. Pesatnya perkembangan teknologi menyebabkan, banyak manusia yang mengharapkan kemudahan di setiap pekerjaannya. Seperti pada industri pembuatan sepatu yang sekarang sudah banyak menggunakan kemajuan teknologi dalam memproduksi sepatu untuk skala yang sangat besar .

Saat ini sudah banyak industri perdagangan yang menggunakan kemajuan teknologi dalam memasarkan produknya, namun masih ada beberapa masalah dalam penjualan, salah satunya sering kali konsumen kesusahan menentukan ukuran sepatunya bisa saja kebesaran atau kekecilan. Dalam mengatasi masalah tersebut diperlukan sebuah alat untuk mengukur panjang telapak kaki konsumen secara otomatis. Sehingga konsumen tidak harus banyak membuang waktu untuk mencoba satu persatu sepatu yang dipasang di pusat perbelanjaan. Konsumen cukup meletakan kakinya pada sebuah alat yang secara otomatis akan mengukur panjang telapak kaki, kemudian akan tampil informasi berupa gambar, merek, model, serta stok sepatu yang cocok sesuai ukuran dan kebutuhan konsumen.

\section{METODOLOGI PENELITIAN}

\subsection{Studi pustaka}

Penelitian ini dimulai dengan studi pustaka di mana penelitian mengumpulkan dan mempelajari literatur yang berkaitan dengan buku-buku serta melakukan observasi yang berkaitan dengan sistem yang dirancang. Selain itu, penulis juga mengambil referensi dari penelitian terdahulu, jurnal-jurnal, buku serta wawancara langsung dengan narasumber yang terpercaya sebagai bahan acuan dalam melakukan penelitian.

\subsection{Analisa kebutuhan}

Tahapan selanjutnya adalah analisa kebutuhan, di mana analisa kebutuhan dibedakan menjadi dua. yakni analisa hardware, di mana pada analisa ini dimulai dengan melihat aspek-aspek terkait estimasi biaya, kemudahan penggunaan sistem, ketersediaan alat di pasaran dan lain-lain. Beberapa perangkat utama yang dibutuhkan adalah mikrokontroler Arduino MEGA, ethernet shield, dan sensor LDR. Software penunjang pemrograman dan perancangan yang dibutuhkan adalah 
Arduino IDE, aplikasi pemrograman website, serta software untuk membuat rangkaian elektronika.

\subsection{Perancangan Hardware dan Software}

Perancangan hardware dan software, Secara umum perancangan mencakup tentang deskripsi sistem, perancangan hardware dan perancangan software.

a. Rancangan Sistem

Berdasarkan kebutuhan yang diperlukan maka berikut adalah perancangan diagram blok sistem

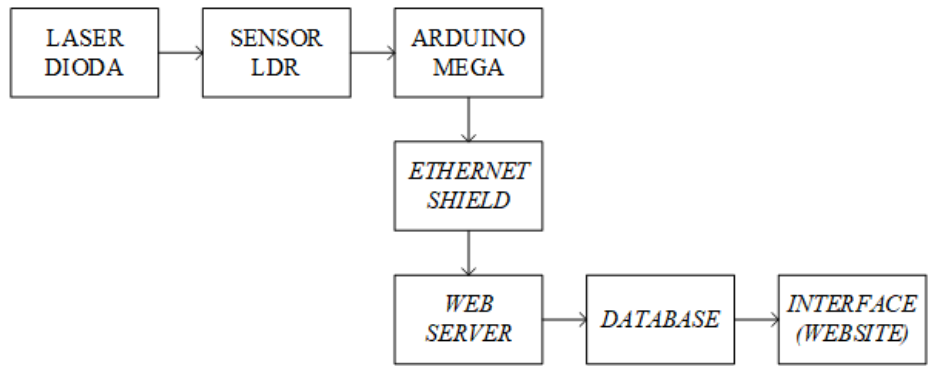

Gambar 1. Diagram blok perancangan sistem

Penjelasan diagram blok perancangan sistem pada Gambar 1 adalah sebagai berikut :

1) Sensor LDR berfungsi sebagai masukan kepada Arduino yang berupa data intensitas cahaya dari laser Dioda.

2) Laser Dioda berfungsi sebagai pemancar cahaya yang ditujukan langsung ke sensor LDR.

3) Arduino MEGA berfungsi sebagai unit pemrosesan data dari sensor LDR dan laser Dioda yang nantinya data akan dikonversi menjadi nilai panjang kaki dalam ukuran centimeter.

4) Ethernet shield berfungsi sebagai penghubung Arduino MEGA dengan jaringan internet.

5) Web server berfungsi mengirim data ke halaman website.

6) Database berfungsi sebagai penyimpanan data stok sepatu yang tersedia.

7) Interface berfungsi sebagai penghubung antara sistem dengan pengguna.

b. Rancangan Hardware

Perancangan hardware dimulai dengan merancang rangkaian alat dengan mengintegrasikan beberapa hardware menjadi sebuah sistem. Perancangan hardware dilakukan untuk merancang rangkaian elektronika, pola komunikasi hardware dan menentukan komponen yang dipergunakan dalam membuat alat. 


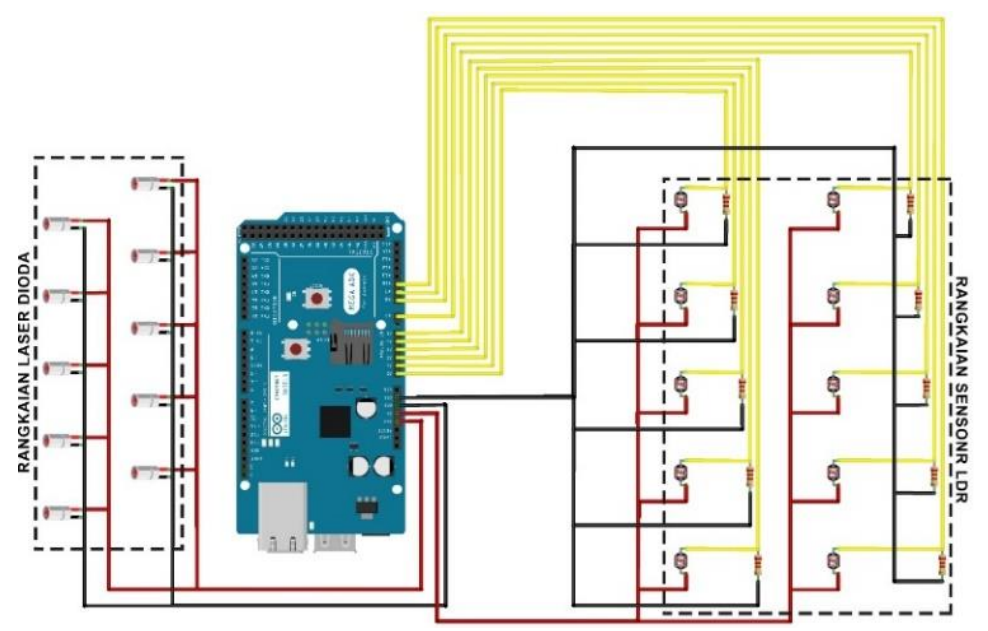

Gambar 2. Rangkaian elektronika alat ukur panjang kaki

Perancangan alat ukur panjang kaki tampak dari atas. Dengan dimensi alat, panjang $42 \mathrm{~cm}$, lebar $35 \mathrm{~cm}$ dan tinggi $5 \mathrm{~cm}$. Terdapat pula kolam di tengahnya sebagai tempat pengukur panjang telapak kaki dengan dimensi panjang $32 \mathrm{~cm}$, lebar $14 \mathrm{~cm}$ dan tinggi $5 \mathrm{~cm}$. Terdapat juga lubang-lubang di bagian kanan dan kiri kolam tempat meletakan sensor LDR dan laser Dioda dengan jarak antar lubang sebesar $0,5 \mathrm{~cm}$. Untuk lebih jelasnya dapat dilihat pada Gambar 3.

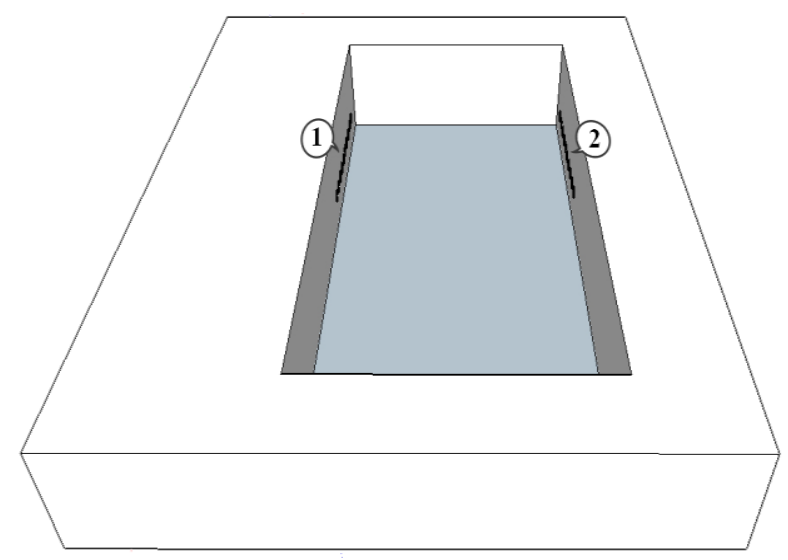

Gambar 3. Purwarupa rancang alat ukur panjang kaki tampak dari atas

c. Rancangan software

Perancangan software pada penelitian ini sangat diperlukan sebagai jembatan penghubung antara perangkat keras ke perangkat lunak. Berdasarkan konsep perancangan hardware, maka program yang dirancang diharapkan dapat mampu mengolah informasi yang nantinya akan digunakan dalam proses pengukur panjang telapak kaki. Informasi yang didapat tersebut akan dikirim ke database untuk diproses lalu ditampilkan ke antarmuka berupa website. Perancangan dan pembuatan software pada sistem ini menggunakan Arduino IDE, untuk perancangan website menggunakan program PHP (Hypertext Preprocessor), dan dalam sebuah website tersebut terdapat database yang dirancang menggunakan MySQL. Rancangan perangkat lunak pada penelitian ini dibuat dalam bentuk rancangan database dan rancangan antarmuka. 
Database pada penelitian ini memiliki fungsi untuk memudahkan penyimpanan data, baik berupa data akun admin dan akun pengguna, data sepatu baik berupa informasi mengenai merek dan tipe sepatu, informasi stok barang, informasi harga dan gambar.

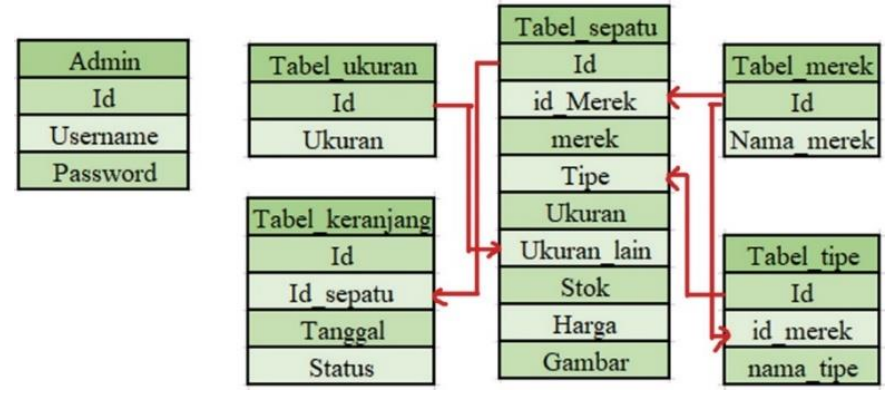

Gambar 4. Relasi Tabel database

Dalam perancangan software ini diperlukan perancangan antarmuka yang merupakan penghubung antara sistem dan pengguna. Berikut adalah gambar tampilan login admin pada aplikasi alat ukur panjang kaki.

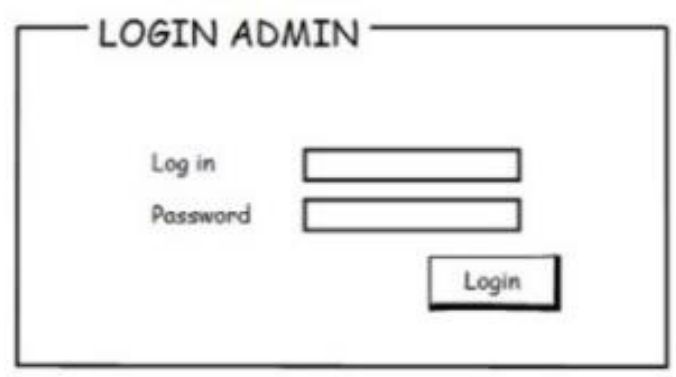

Gambar 5. Tampilan login

Gambar 6 adalah rancangan tampilan admin yang berguna sebagai pengontrol stok barang. Terdapat beberapa menu antara lain "data sepatu" yang menampilkan stok sepatu apa saja yang terdapat di dalam gudang. Di menu ini admin dapat menambahkan, mengurangkan, dan mengubah data sepatu.

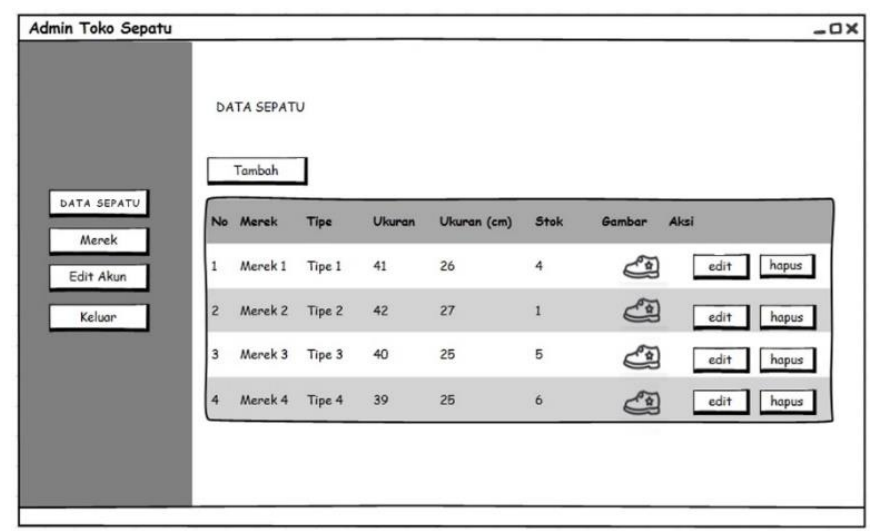

Gambar 6. Tampilan halaman admin

Gambar 7 adalah rancang tampilan admin yang terdapat pada menu "merek", di menu ini admin dapat menambahkan merek sepatu apa saja dengan 
memasukkan nama merek lalu meng-klik tombol tambah. Admin juga dapat menghapus serta mengubah nama merek sepatu dengan tombol "hapus" dan "edit". Selain itu juga terdapat fitur tambah tipe dari setiap merek sepatu. Setelah penginputan merek sepatu dilakukan maka nantinya di teruskan di menu "data sepatu" untuk mengisi data serta jenis, ukuran serta stok sepatu.

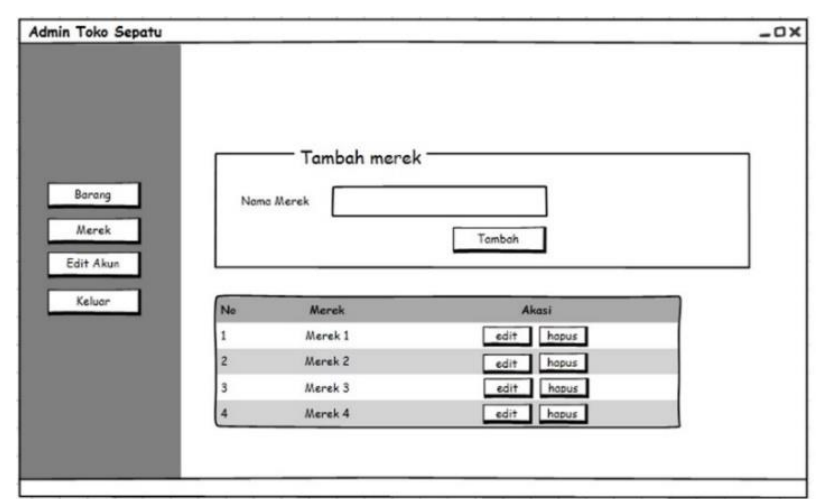

Gambar 7. Halaman admin di menu merek

Gambar 8 adalah rancang tampilan admin yang terdapat pada menu "edit akun". Di dalam menu ini admin dapat mengubah password sesuai kebutuhan admin dengan mengisi form username dan password lalu klik tombol "ubah". Menu berikutnya adalah "keluar", digunakan untuk keluar setelah selesai mengatur stok barang dengan meng-klik tombol "keluar".

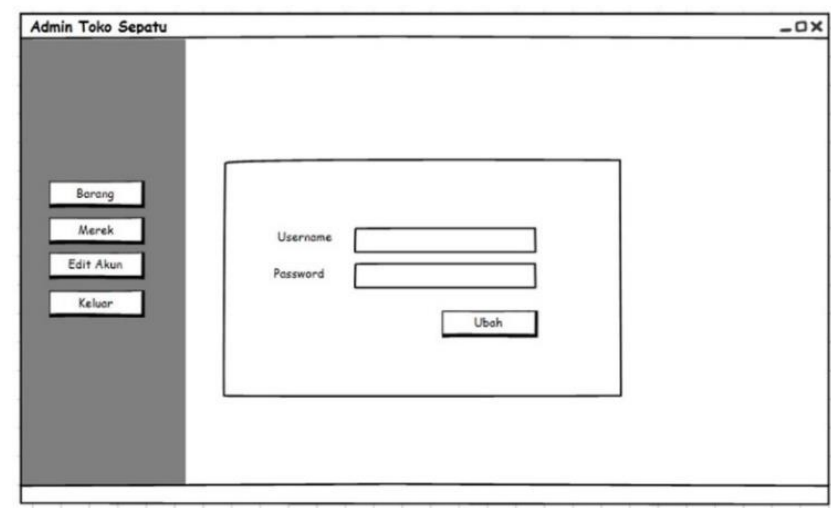

Gambar 8. Tampilan halaman admin di menu edit akun

Gambar 9 adalah rancang tampilan pengguna yang nantinya setelah pengguna melakukan pengukuran dengan alat ukur panjang kaki, maka akan tampil beberapa stok sepatu yang sesuai dengan ukuran kaki pengguna. 


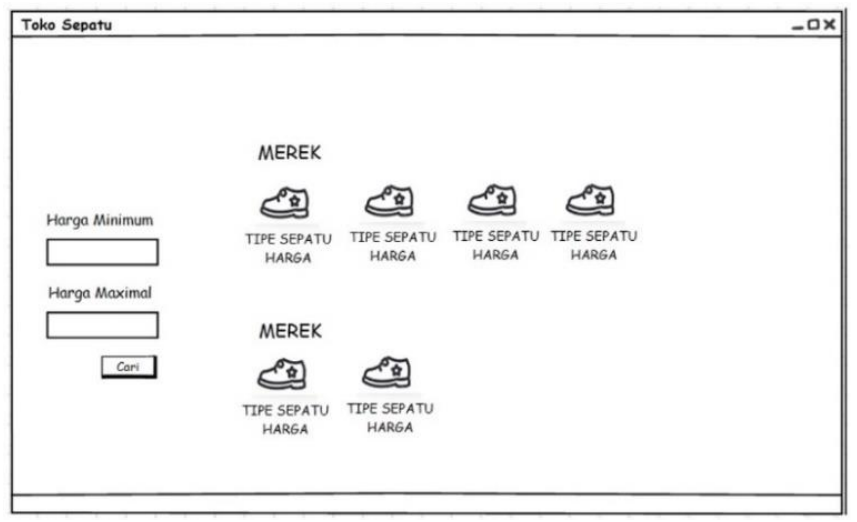

Gambar 9. Tampilan halaman pengguna

\section{HASIL DAN PEMBAHASAN}

Setelah melakukan proses perancangan, tahapan selanjutnya melakukan implementasi dan uji coba sistem yang merupakan tahapan akhir pada penelitian ini.

\subsection{Hasil perancangan software}

Hasil perancangan software menampilkan kinerja antar muka yang sudah di buat sesuai kebutuhan alat ukur panjang kaki. Berikut adalah tampilan halaman login pada website alat ukur panjang kaki. Dalam hal ini hanya admin yang dapat masuk dan mengatur konten.

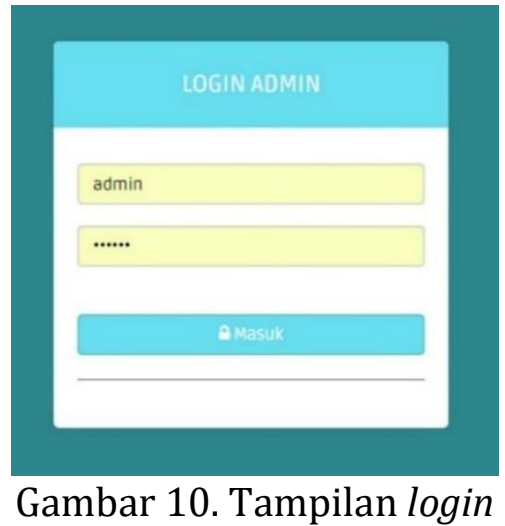

Gambar 11 adalah tampilan admin dari aplikasi alat ukur panjang kaki, terdapat beberapa menu yang di tampilkan yaitu menu stok sepatu, menu merek, menu edit akun, dan menu keluar. Pada menu stok sepatu menampilkan stok sepatu yang terdapat dalam gudang, meliputi data sepatu seperti merek, tipe, ukuran, stok, harga serta gambar. Terdapat kolom ubah dan hapus yang berguna untuk mengubah data sepatu serta menghapus data sepatu. Selain itu di dalam tabel stok terdapat 3 warna yang menyatakan stok sepatu, merah menandakan stok sepatu kosong, kuning menandakan stok sepatu kurang dari 5, dan transparan menandakan stok sepatu lebih dari 5. 


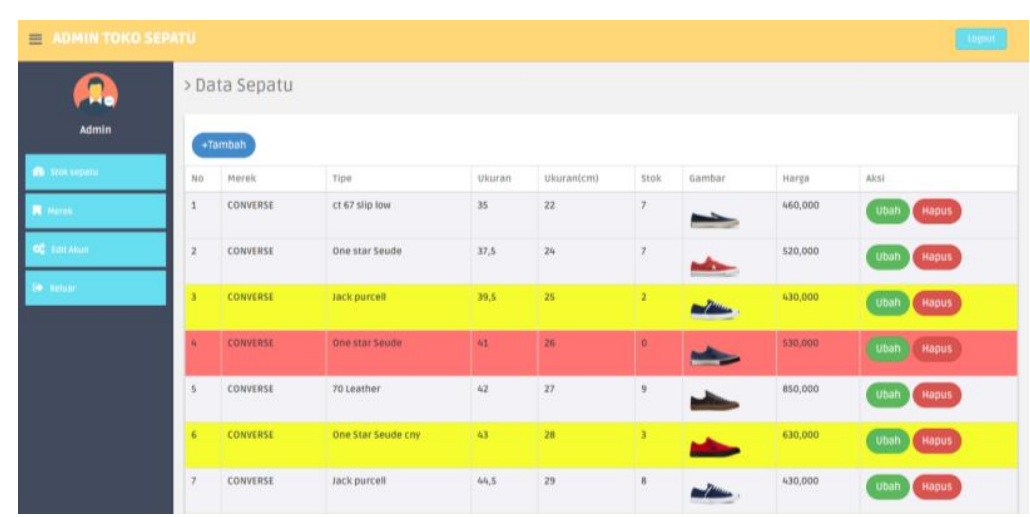

Gambar 11. Tampilan admin

Gambar 12 adalah tampilan admin pada menu tambah merek, menu tambah merek berfungsi menambahkan merek pada data sepatu yang nantinya akan diinput. Di dalam menu merek ini juga terdapat dua aksi yaitu edit dan hapus, kedua aksi ini berguna untuk mengubah nama dan menghapus data merek.

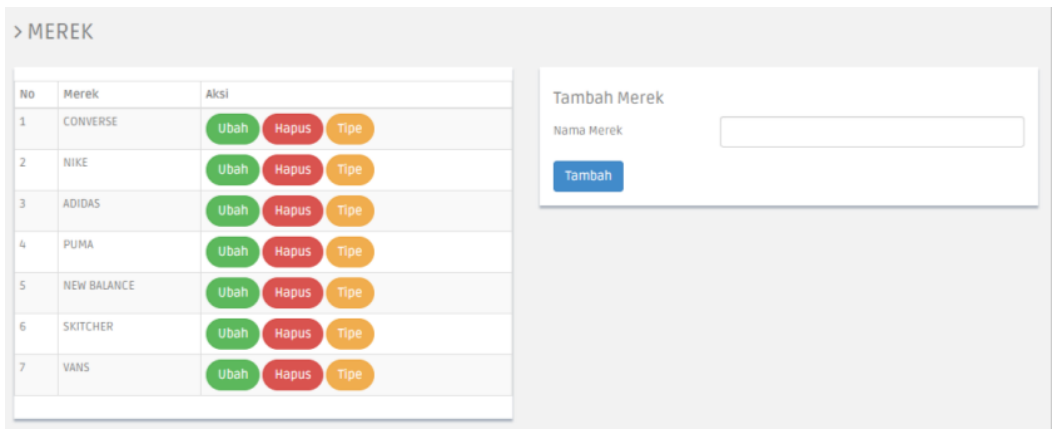

Gambar 12. Tampilan admin menu merek

Gambar 13 adalah tampilan admin pada menu edit akun, menu edit akun ini berfungsi untuk mengubah password admin dengan cara mengisi form yang tersedia sesuai kebutuhan. Menu berikutnya adalah "keluar", digunakan untuk keluar setelah selesai mengatur stok barang dengan meng-klik tombol "keluar".

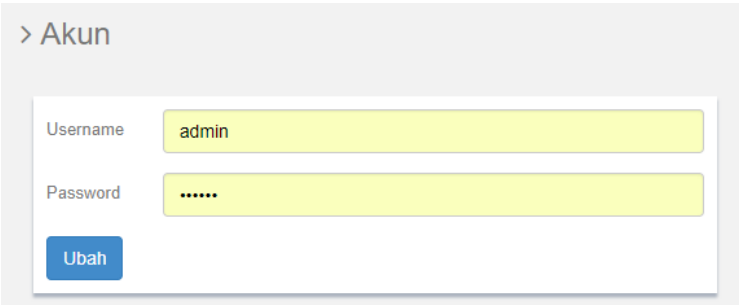

Gambar 13. Tampilan admin pada menu edit akun

Gambar 14 adalah tampilan halaman pengguna, berfungsi menampilkan sepatu yang cocok. Di dalam halaman pengguna ini terdapat dua form yang berfungsi sebagai penyortir harga sepatu, harga sepatu dapat disortir sesuai kebutuhan pengguna menyesuaikan anggaran pengguna. Selain itu juga di dalam tampilan halaman pengguna juga terdapat menu detail yang menampilkan data informasi dari sepatu yang dipilih. 


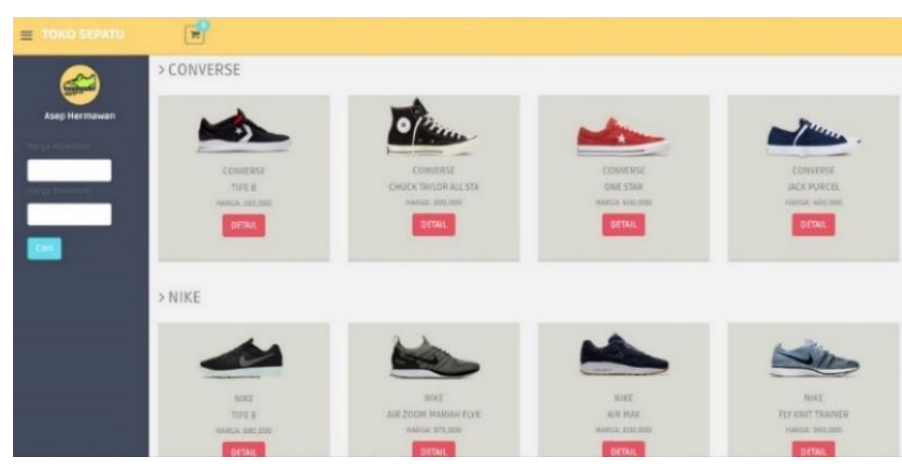

Gambar 14. Tampilan halaman pengguna aplikasi alat ukur panjang kaki

\subsection{Hasil Perancangan Hardware}

Berikut adalah parameter panjang telapak kaki pada alat ukur panjang telapak kaki sebagai berikut, jika panjang telapak kaki uji sepanjang $21-21,9 \mathrm{~cm}$, maka sensor yang akan terhalang sebanyak 1 pasang dan menghasilkan keluaran di halaman website sepatu dengan ukuran $22 \mathrm{~cm}$. Begitu selanjutnya seperti pada tabel 1.

Tabel 1. Data sensor ukuran sepatu

\begin{tabular}{ccc}
\hline $\begin{array}{c}\text { Pengukuran } \\
\text { manual }(\mathrm{cm})\end{array}$ & $\begin{array}{c}\text { Sensor yang } \\
\text { terhalang }\end{array}$ & $\begin{array}{c}\text { Pengukuran } \\
\text { digital }(\mathrm{cm})\end{array}$ \\
\hline $21-21,9$ & 1 & 22 \\
$22-22,9$ & 2 & 23 \\
$23-23,9$ & 3 & 24 \\
$24-24,9$ & 4 & 25 \\
$25-25,9$ & 5 & 26 \\
$26-26,9$ & 6 & 27 \\
$27-27,9$ & 7 & 28 \\
$28-28,9$ & 8 & 29 \\
$29-29,9$ & 9 & 30 \\
$30-30,9$ & 10 & 31 \\
\hline
\end{tabular}

Hasil perancangan hardware menampilkan hasil pengukuran alat ukur panjang kaki. Berikut adalah proses pengukuran panjang telapak kaki dengan meletakkan kaki langsung pada alat ukur panjang telapak kaki.

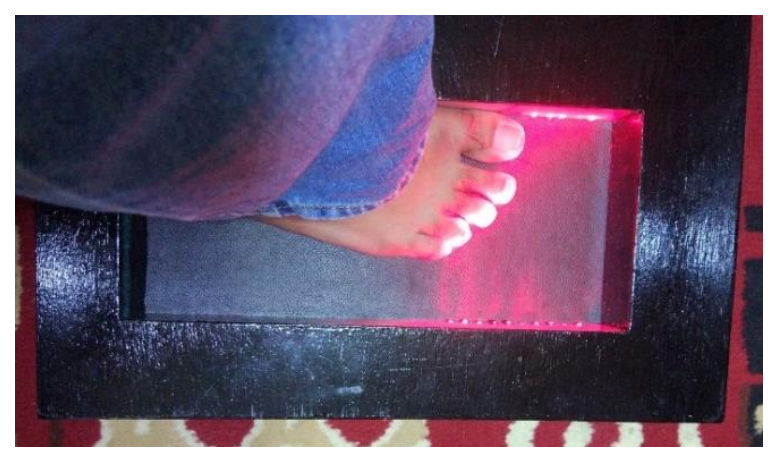

Gambar 15. Proses pengukuran 
Selanjutnya data dari alat akan diproses, berikut tampilan serial monitor jika terdapat kaki yang menghalangi sensor LDR dan laser dioda.

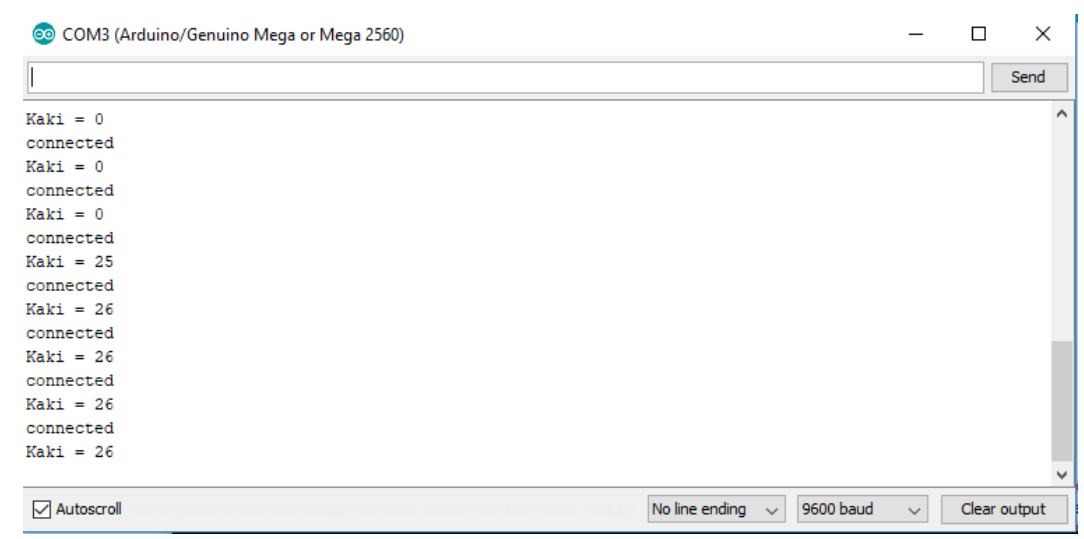

Gambar 16. Pengiriman data panjang kaki pada serial monitor

Pada baris 1 dan 2 tertulis "Kaki = 0, Connected" pada jendela serial monitor yang berarti tidak ada kaki yang menghalangi sensor LDR dan laser Dioda, dan status Connected berarti alat ukur panjang kaki sudah terhubung dengan laptop. Pada baris 9 dan 10 tertulis "Kaki = 26 Connected" pada jendela serial monitor yang berarti 5 sensor LDR dan laser Dioada terhalang oleh telapak kaki, dan status Connected berarti alat ukur panjang kaki sudah terhubung dengan laptop. Selanjutnya data yang di dapat akan di tampilkan ke dalam website setelah proses pencocokan di dalam database. Berikut adalah tampilan website.

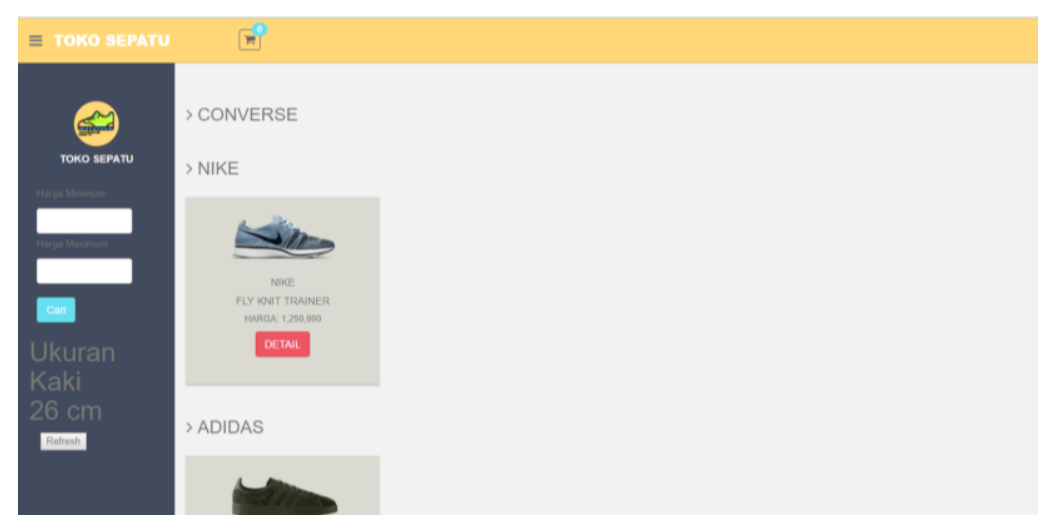

Gambar 17. Stok sepatu yang tersedia

Pada Gambar 17 panjang telapak kaki di tampilkan pada halaman website bagian bawah sebelah kiri. Tertulis "Ukuran Kaki $26 \mathrm{~cm}$ ", yang berarti website hanya menampilkan sepatu yang tersedia di ukuran $26 \mathrm{~cm}$ beserta gambar sepatu yang tersedia.

Selanjutnya akan dilakukan pengujian langsung terhadap 40 orang pengguna sepatu berbagai merek. Pengujian dilakukan dengan dua cara yaitu manual dan digital. Dalam pengujian manual di bagi lagi menjadi yaitu pengukuran manual menggunakan penggaris dan melihat langsung ukuran sepatu yang dipakai pengguna. Dalam pengujian digital di bagi juga menjadi dua yaitu sensor yang terhalang dan ukuran sepatu yang ditampilkan dalam halaman website. 
Tabel 2. Hasil pengukuran manual dan digital

\begin{tabular}{|c|c|c|c|c|c|c|c|c|}
\hline \multirow[b]{2}{*}{ No. } & \multirow[b]{2}{*}{ Nama } & \multicolumn{2}{|c|}{ Manual } & \multicolumn{2}{|c|}{ Digital } & \multicolumn{2}{|c|}{ Selisih } & \multirow[b]{2}{*}{ Keterangan } \\
\hline & & $\begin{array}{l}\text { Pengukuran } \\
\text { manual } \\
(\mathrm{cm})\end{array}$ & $\begin{array}{l}\text { Ukuran } \\
\text { sepatu } \\
\text { yang } \\
\text { dipakai } \\
\text { (cm) }\end{array}$ & $\begin{array}{l}\text { Sensor } \\
\text { yang } \\
\text { menyala }\end{array}$ & $\begin{array}{l}\text { Ukuran } \\
\text { sepatu } \\
\text { digital } \\
(\mathrm{cm})\end{array}$ & $\begin{array}{l}\text { Selisih } \\
\text { manual }\end{array}$ & $\begin{array}{l}\text { Selisih } \\
\text { digital }\end{array}$ & \\
\hline 1 & Ison & 25 & 26 & 5 & 26 & 1 & 0 & Berhasil \\
\hline 2 & Firza & 23,3 & 24,5 & 3 & 24 & 1,2 & 0,5 & Berhasil \\
\hline 3 & Ari & 25,5 & 26,5 & 5 & 26 & 1 & 0,5 & Berhasil \\
\hline 4 & Asep & 25,7 & 27 & 5 & 26 & 1,3 & 1 & Berhasil \\
\hline 5 & Laili & 24,6 & 25 & 4 & 25 & 0,4 & 0 & Berhasil \\
\hline 6 & Riki & 24,5 & 25 & 4 & 25 & 0,5 & 0 & Berhasil \\
\hline 7 & Joko & 24,7 & 25,5 & 4 & 25 & 0,8 & 0,5 & Berhasil \\
\hline 8 & Ricky & 26,3 & 27 & 6 & 27 & 0,7 & 0 & Berhasil \\
\hline 9 & Visca & 23,8 & 24,5 & 3 & 24 & 0,7 & 0,5 & Berhasil \\
\hline 10 & Noela & 24,2 & 25,5 & 4 & 25 & 1,3 & 0,5 & Berhasil \\
\hline 11 & Dodo & 25,5 & 26 & 5 & 26 & 0,5 & 0 & Berhasil \\
\hline 12 & Frida & 24,6 & 25,5 & 4 & 25 & 0,9 & 0,5 & Berhasil \\
\hline 13 & Nana & 23,7 & 25 & 3 & 24 & 1,2 & 1 & Berhasil \\
\hline 14 & Zuppa & 25,3 & 26 & 5 & 26 & 0,7 & 0 & Berhasil \\
\hline 15 & Doca & 24,4 & 25,5 & 4 & 25 & 1,1 & 0,5 & Berhasil \\
\hline 16 & Frans & 28,5 & 29,5 & 8 & 29 & 1 & 0,5 & Berhasil \\
\hline 17 & Amat & 27,2 & 28 & 7 & 28 & 0,8 & 0 & Berhasil \\
\hline 18 & Zulfikar & 25 & 26 & 5 & 26 & 1 & 0 & Berhasil \\
\hline 19 & Puja & 27,6 & 28,5 & 7 & 28 & 0,9 & 0,5 & Berhasil \\
\hline 20 & Made & 23,7 & 24,5 & 3 & 24 & 0,8 & 0,5 & Berhasil \\
\hline 21 & Tela & 23,3 & 24 & 3 & 24 & 0,7 & 0 & Berhasil \\
\hline 22 & Kinta & 24,6 & 25,5 & 4 & 25 & 0,9 & 0,5 & Berhasil \\
\hline 23 & Mita & 24,3 & 25,5 & 4 & 25 & 1,2 & 0,5 & Berhasil \\
\hline 24 & Ipeh & 25,4 & 26,5 & 5 & 26 & 1,1 & 0,5 & Berhasil \\
\hline 25 & Mayang & 24,7 & 25,5 & 4 & 25 & 0,8 & 0,5 & Berhasil \\
\hline 26 & Damar & 26,4 & 27 & 6 & 27 & 0,6 & 0 & Berhasil \\
\hline 27 & Alif & 25,3 & 26 & 5 & 26 & 0,7 & 0 & Berhasil \\
\hline 28 & Ardi & 26,7 & 27,5 & 6 & 27 & 0,8 & 0,5 & Berhasil \\
\hline 29 & Gilang & 26,2 & 27 & 6 & 27 & 0,8 & 0 & Berhasil \\
\hline 30 & Ratna & 24,6 & 25,5 & 4 & 25 & 0,9 & 0,5 & Berhasil \\
\hline 31 & Gama & 27 & 28 & 7 & 28 & 1 & 0 & Berhasil \\
\hline
\end{tabular}

Lanjutan Tabel 2. Hasil pengukuran manual dan digital

\begin{tabular}{lllll}
\hline No. Nama & Manual & Digital & Selisih & Keterangan \\
\hline
\end{tabular}




\begin{tabular}{ccccccccc}
\hline & & & & & & & & \\
\hline
\end{tabular}

Setelah diperoleh data pengukuran, maka analisis eror yang terjadi dengan rumus sebagai berikut :

selisih manual $=(F 2-F 1) \leq 1,5$

Selisih Digital $=(F 2-F 4) \leq 1$

Keterangan :

$\mathrm{F} 1$ = pengukuran manual

F2 = ukuran sepatu yang dipakai

F3 = sensor yang terhalang

F4 = Ukuran yang disarankan

Berdasarkan pengujian pengukuran panjang kaki yang dilakukan sebanyak 40 sample. Terdapat toleransi untuk mengukur selisih manual jika hasil dari F2 dikurang dengan F1 kurang dari sama dengan 1,5 maka hal tersebut dinyatakan berhasil, namun jika hasil dari F2 dikurang dengan F1 lebih dari 1,5 maka hal tersebut dinyatakan gagal. Sedangkan untuk mengukur selisih nilai digital jika hasil dari F2 dikurang dengan F4 kurang dari sama dengan 1 maka hal tersebut dinyatakan berhasil, namun jika hasil dari F2 dikurang dengan F4 lebih dari 1 maka hal tersebut dinyatakan gagal.

\section{SIMPULAN}

Berdasarkan hasil perancangan implementasi dan pengujian ditarik kesimpulan sebagai berikut :

a. Dengan penggunaan website ini dapat memberikan informasi stok sepatu yang tersedia kepada pengguna agar lebih mudah menentukan ukuran sepatu yang sesuai dengan ukuran telapak kaki pengguna.

b. Hasil pengujian alat digital diperoleh selisih antara $0 \mathrm{~cm}-1 \mathrm{~cm}$ dengan toleransi sebesar $1 \mathrm{~cm}$. Hasil pengukuran panjang kaki manual diperoleh selisih antara $0,4 \mathrm{~cm}-1,5 \mathrm{~cm}$ dengan toleransi sebesar $1,5 \mathrm{~cm}$. Nilai selisih yang terukur disebabkan oleh pengguna yang memakai sepatu sesuai ukurannya dan ada juga pengguna yang melebihkan ukuran sepatunya agar nyaman di pakai.

c. Berdasarkan hasil pengujian perangkat secara keseluruhan didapatkan tingkat keberhasilan sebesar $100 \%$ untuk 40 data sampel. 


\section{DAFTAR PUSTAKA}

[1] Djuandi, F. 2005. Pengenalan Arduino. Jakarta; Elexmedia.

[2] Saleh. C, "Pengukuran Pemindahan Teknologi di Industri Manufaktur Otomotif Melalui Pendekatan DEA" Jurnal Transistor, vol. 5, No. 1, 2005.

[3] Rohmayati. A, "Sistem Informasi Persediaan Obat Pada Toko Obat Segar Waras Depok" Jurnal Bianglala Informatika, Vol. 5, No. 2, 2017.

[4] Kustiana, Akbar. W. A., Rachmat, Handian. H, "Perancangan dan Realisasi Box Alat Ukur Panjang Badan Balita Elektronik Berbasis Personal Computer" Jurnal Elektro dan Telekomunikasi Terapan, Vol. 4, No. 2, Desember 2017.

[5] Tarsono. I, "Prototype Pemisah Otomatis Jeruk Siam Berdasarkan Warna Menggunakan Metode KNN (K-Nearest Neighbor)" Jurnal Coding Sistem Komputer Universitas Tanjungpura, Vol. 6, No. 1, 2018

[6] Mandarani. P, "Perancangan dan Implementasi User Interface Berbasis Web Untuk Monitoring Suhu, Kelembaban dan Asap Pada Ruangan Berbeda Dengan Memanfaatkan Jaringan Local Area Network" Jurnal TEKNOIF, Vol. 2, No. 2, Oktober 2014

[7] Novita. R, "Sistem Informasi Penjualan Pupuk Berbasis E-Commerce", Jurnal Teknoif, Vol. 3, No. 2, 2015. 